\title{
DNA Sequencing
}

National Human Genome Research Institute (NHGRI)

\section{Source}

National Human Genome Research Institute (NHGRI). DNA Sequencing.

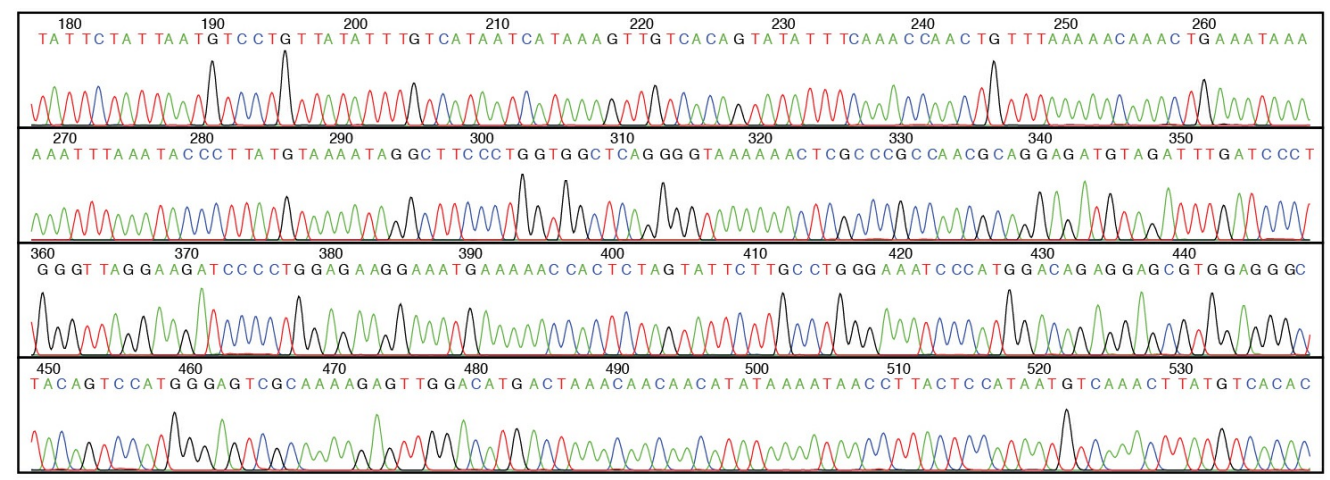

DNA sequence data from an automated sequencing machine

DNA sequencing is a laboratory technique used to determine the exact sequence of bases ( $A, C, G$, and $T$ ) in a DNA molecule. The DNA base sequence carries the information a cell needs to assemble protein and RNA molecules. DNA sequence information is important to scientists investigating the functions of genes. The technology of DNA sequencing was made faster and less expensive as a part of the Human Genome Project. 